\title{
Inshore fisheries development in Fiji
}

\author{
Joeli Veitayaki
}

Inshore fisheries, which includes the artisanal and subsistence sectors, is arguably one of the most important resource sectors in the Fiji economy, but it is undervalued and poorly understood. Its value and contribution is still based on estimates. However, the value of inshore fisheries is substantial for a variety of reasons, including its contribution to the protein requirements of the majority of the population, the savings to the economy through import substitution, the livelihood of the people who rely on it for income and employment, and the increasingly threatened nature of the resource due to changing environmental conditions (South Pacific Commission (SPC) 1994).

The recent survey of subsistence and artisanal fisheries in Fiji noted that on Viti Levu, half the households interviewed have at least one member who fishes. Two-thirds of them fish for subsistence and one-third are artisanal operators who supply their villages and the urban markets (Rawlinson et al. 1995). The survey estimated the total annual catch on Viti Levu at some 10,000 tonnes, with the subsistence catch accounting for 3,500 tonnes and artisanal 6,206 tonnes. At the weighted mean 1996 price of $F \$ 3.75$ per kilogram, the total value of subsistence and artisanal fisheries on Viti Levu alone would be around F\$37.5 million (Ministry of Agriculture, Fisheries and Forests 1996). The Fisheries Division estimated the inshore supply for the country in 1996 at around 23,000 tonnes which, with the weighted mean value of $\mathrm{F} \$ 3.75$ per kilogram, was worth $\mathrm{F} \$ 86$ million (Ministry of Agriculture, Fisheries and Forests 1996). During the same period, the artisanal sector contributed 4,580 tonnes of finfish worth F $\$ 17.18$ million and 2,148 tonnes of non-finfish worth some F\$8.06 million.

The total subsistence production for Fiji for 1999 is estimated to be around 17,800 tonnes. This is based on a figure of 14,000 tonnes for 1980 and a 
yearly increase of 200 tonnes. The retail price ranges between $\mathrm{F} \$ 1$ and $\mathrm{F} \$ 10$ per kilogram. At the weighted mean price of $F \$ 5.75$ per kilogram, this fishery will be worth approximately $F \$ 102.4$ million. The reliability of these estimations is difficult to judge, but the importance of the fisheries sector to the national economy is beyond doubt.

Since 1995, the Fisheries Division has been trying to undertake the second phase of the subsistence and artisanal fisheries survey, but it has been hampered by lack of funds. This remains a major concern, because it will be difficult to understand the contribution of inshore fisheries unless more information is made available on its contribution and status. All the current planning, policies and strategies are based on estimates from a survey in the late 1970s.

Over the last decade, the development and management of inshore fisheries has become an important priority because of its importance to the local economy and its vulnerability to over-exploitation. Local community groups dominate inshore fisheries, which are labour intensive and flexibly organised. As both the population and coastal development increase and technology improves the power of inshore fishers, it is crucial that the management of the reef and lagoon fisheries resources be improved. This is important because the national desire for self-sufficiency and maximum inshore fisheries production has to be balanced with the need for prudent management and the sustainable use of the resources (Kailola 1995; Pita 1996).

\section{Fisheries development policy}

Fisheries development objectives during the Development Plan 7 period (1976-80) were to: promote and consolidate the development of village and commercial fisheries in order to provide additional income especially in areas where fish resources were adequate but agricultural potential low; develop local capability to fish skipjack tuna through appropriate institutional arrangements; encourage the commercial development of fish, oysters and other marine species of animals and plants; avoid overexploitation of fisheries resources; train fishers and bring extension workers to test, modify and develop appropriate technology to increase the efficiency of fisheries enterprises; encourage the processing of fish and other fishery products in Fiji; provide adequate and effective machinery for inspection, protection services, law enforcement and regulatory activities; and liaise closely with other fisheries agencies in the region (Fiji, Central Planning Office 1975).

During this period, the emphasis was on the development of smallscale artisanal fisheries through the introduction of motorised craft; improvements in fishing gear and methods; processing of export items; establishment of a marketing and transportation system, ice making, and 
storage plants; and the improvements of landing and berthing facilities at the main fishing centres. The National Marketing Authority (NMA), a statutory body, was created to purchase, distribute and market fish and fish products nationwide. At the same time, fish culture trials were conducted in Raviravi, Naduruloulou and other parts of the country.

Between 1981 and 1990, the period of Fiji's eighth and ninth development plans (DP8 and DP9), the major objectives of the fisheries sector were to generate further employment opportunities in the exploitation and processing of marine resources, increase production for local consumption, enhance the value added in fish production for exports, and to regulate and control the exploitation of fin and non-fin fishery products (Fiji, Central Planning Office 1985).

To pursue these objectives, the Fisheries Division promoted four major fisheries sector programs.

1 The Rural Fisheries Development Program, designed to

- promote the development of the fisheries potential of remote regions of the country

- provide basic protein requirement

- create further opportunities for employment and income generation and integrate rural communities into the formal sector of the economy.

2 The Commercial Artisanal Fisheries Development Program, designed to

- provide suitable fishing vessels to commercial fishers to enable them to fish around the reef in areas more distant from larger urban centres

- ensure adequate ice supply, storage, improved markets, fishing gear and equipment provide technical assistance, training and facilitate credit

- provide berthing and slipping facilities.

3 The Industrial Fisheries Development Program, designed to

- expand the skipjack tuna industry

- expand the utilisation of tuna-processing capacity and

- encourage alternative fishing methods such as purse-seining and longlining or a combination of such methods where applicable.

4 The Rural Aquaculture Extension Program, designed to

- provide an alternative protein source for the inland population, release grass carp into rivers and waterways throughout Fiji as a biological control measure for introduced water weeds

- provide fish fry to fish farmers as part of government support

- promote fish farming as a viable business and a source of employment in the rural sector

- provide training to fish farmers. 
Two of the above programs ( 1 and 2) concern the utilisation of inshore resources, which illustrates the importance of the sector. However, most of the failed fisheries projects referred to here were formulated during this period, when government policy favoured decentralisation through the deployment of infrastructure and extension staff to rural areas. Unfortunately, this strategy resulted in the over-exploitation of inshore fisheries and caused the collapse of the fisheries development activities.

Under the Rural Fisheries Development Program, several rural fisheries schemes and fisheries cooperatives were established in various parts of the country, and people were encouraged to take up artisanal fisheries. A number of schemes such as the 'West' Hurricane Oscar Fisheries Rehabilitation Program (Evening 1983) involved the collection of fisheries products by vessels or trucks from predetermined collection points for sale in the urban markets. The scheme was geared for chilled fresh fish rather than frozen fish. Hence, five one-tonne per day ice plants and 20 three-tonne iceboxes were provided for the scheme (Shepard and Clark 1984). All these projects were aimed at allowing people in distant rural areas access to the high prices in urban areas, enabling them to improve their living conditions.

Under the Commercial Artisanal Fisheries Development Program, people were encouraged to improve their fishing technology and gear through the Rural Fisheries Training Program (RFTP) and take follow-up extension courses. People in rural areas were to undergo training to enable them to be competent artisanal fishers. Each of the trainees attending the RFTP was provided with a Fiji Development Bank loan to buy a subsidised FAO-designed 28-foot fishing boat. In many cases, the fishers were also given fishing gear and equipment. For instance, diesel engines, winches, fish finders, nets and other equipment were supplied free to the fishers through Japanese aid (Shepard and Clark 1984). The expectation was that the villagers would become fishers to repay their loans and to improve their living conditions.

Under the Rural Aquaculture Extension Program, the Fisheries Division promoted the cultivation of prawns, carp and other suitable species and seaweed in many coastal communities throughout the country. It was hoped that aquaculture, which has been proven to be technically feasible, would provide food, employment and income to the people involved. The Raviravi fish farm was initiated as a joint Lands Department-Fisheries Division project to determine the potential of fish farming on reclaimed marshes. Dense lowcropped mangroves were cleared to make way for the ponds. Until 1978, various species such as rabbit fish, mullet and milkfish were tested. The project was abandoned due to the failure to establish commercial viability.

In 1981, the fish farming in Raviravi was resumed by the Fiji government and France Aquaculture, a French government-funded organisation. The joint venture was to investigate the feasibility of saltwater prawn (Penaeus/ 
Monodon) farming and to establish its potential for commercial production. The development was to be in three phases, each depending on the success of the previous one. Although the production results from phase one were encouraging, all the goals for the phase were not met due to unforeseen problems. Nonetheless, it was proposed that the project progress to phase two to make the project operational. However, despite the involvement of local private sector interests, FDB Nominees Limited, the project stalled there because of unforeseen problems.

As a result of the problems faced in the implementation of these DP7 and DP8 fisheries development programs, the Fisheries Division revised its position towards the end of the DP9 period. It decided to channel fisheries development away from inshore to offshore exploitation, adding value to products and moving capture fisheries towards cultivation methods.

The priorities of the 1990s placed more emphasis on management and control of resources, acknowledging the need to encourage fishermen to move offshore to preserve the inshore fisheries. The broad objectives in the development of Fiji's fisheries sector were to further develop fisheries of the Exclusive Economic Zone (EEZ) and territorial waters; improve the quality of, and increase value added to, exports; regulate and control all fisheries on the principles of optimum utilisation and long term sustainability and encourage the implementation of sound business management methods by cooperation between local fishermen and, to devolve, as far as possible, government activities to the private sector.

Some of the initiatives underpinning these policies have included the establishment of a bêche-de-mer producers' association (now defunct), the development of a Fish Aggregation Device (FAD) program, strengthening of the rural aquaculture extension program, and the redeployment of the commercial seaweed program. In addition, the Fiji Trade and Investment Board (FTIB) administers a series of incentives for potential investors interested in the development of resources outside the customary fishing areas; those that involve collection, processing and marketing of resources currently exploited, and fish farming (Richards et al. 1994).

The Fiji government's National Environment Strategy (Government of Fiji 1993) emphasised resource management, posing questions such as whether it was necessary for the country to pay the price of a degraded environment in order to attain material improvement; whether there was basic incompatibility between sound environmental and development policies; and whether sustainable economic growth required the conservation of natural resources as the fundamental base for productive activity.

The government's position in relation to these questions was contained in its 1993 paper Opportunities for Growth: policies and strategies for Fiji in the medium term (Government of the Republic of Fiji 1993). The policies and strategies for fisheries were to: expand and consolidate tuna fisheries within 
Fiji's EEZ under the industrial fisheries program; encourage greater efficiency and improve the quality of fish available to consumers in the small-scale commercial fisheries sector; assist rural fishermen in their transition from subsistence to small-scale commercial fishing; develop aquaculture through continued research into appropriate production technologies and extension programs; extend the EEZ and the territorial water fisheries; improve the quality and increase the value-added components of exports; regulate and control all fisheries on the principles of optimum utilisation and long-term sustainability; encourage the implementation of sound business management methods by local fishers; and to improve the handling and processing of domestic fisheries.

To implement these policies, it is important for the government to provide the social and economic environment in which the private sector can flourish and develop the fisheries resources. The government's intervention, therefore, should only be in areas where the private sector should not or cannot invest (Nichols and Moore 1985) and the private sector should be encouraged to be involved in the processing and distribution of fish. In addition, these policies require an integrated planning approach to project formulation, design and implementation and a comprehensive strategy for the development of the inshore fisheries. For this, there is a need to have quality databases and information systems to provide the basis for good decision making. The government has to improve its capacity for data collecting and analysis.

Human resources development is required to ease the transition to commercial fisheries and the proper management of the inshore fisheries. It is also required to ease the transition to the consistent production of highquality fish products. Training is therefore required in the post-harvest handling of fish, the proper management of fisheries operations and ventures, and the control of fishing effort to ensure the sustainability of the sector. There is need to review the procedures regarding the granting of fishing permits to externals by the owners of customary fishing rights areas.

The thrust of the Policies and Strategies for Fiji in the Medium Term was reiterated in Part xiv of the draft Sustainable Development Bill relating to fisheries conservation and management. The Bill aims to: conserve and manage Fiji's fisheries in the interests of present and future generations; promote the broad application of a cautionary approach to the conservation, management and exploitation of marine resources in order to protect and preserve the marine environment, protect fish habitats and prevent the pollution of waters frequented by fish; encourage management of fisheries on a sustainable basis, protecting their economic viability for persons engaged in fishing and fish processing and for the wellbeing of the communities that are dependent on these resources; and encourage the participation of persons engaged in fishing at the domestic, subsistence or 
commercial levels in decisions regarding the conservation and management of fisheries (Government of the Republic of Fiji 1993, 1997a, 1997b).

In addressing the above concerns at the end of 1997 the Ministry of Agriculture initiated the controversial Commodity Development Framework (CDF). A total of F\$69 million was earmarked to revamp the agricultural sector. The CDF reflects the policy change from intervention to deregulation, private sector development and export-led growth. It emphasises diversification as the basis of agricultural development in Fiji and considers the need to commercialise agricultural products for export (Leweniqila 1999).

Although the aims of the CDF are laudable, its specific targets are ambitious and its delivery inefficient. There is no proper control. Indeed, there are allegations that the CDF is misconceived, misguided and mismanaged. Although the government wanted partnership with the private sector, it did not consult it. Instead, the CDF was used to bail out ailing industries such as PAFCO and the copra mills and to fund the purchase of vehicles and overseas travel. The control of the fund is such that even government does not know how much of the money has been spent and on what. Claims have also been made that the government's aim to increase annual income from commodities by more than F $\$ 745$ million through the CDF is excessive (Fiji Times 25 November 1997 editorial). It is not surprising then, that one of the first things the Chaudhry government did was to review and subsequently suspend the CDF.

\section{Inshore fisherles development issues}

In spite of the changing strategies reflecting the shift in policies, inshore fisheries development in Fiji has been indecisive, problematic and expensive. The high number of failed inshore fisheries developments have been costly, resulting in the wastage of already scarce resources. In addition, such failures demoralise and demotivate the people involved and impede fisheries development initiatives (Liew 1990:77-86).

Although fish production has increased considerably, the bulk of the fishing is still conducted in the inshore areas, raising concern about the health of the fisheries stock. Fish handling and distribution has improved but these are still restricted to areas around the main centres. The changes have not significantly affected the price of value-added products. The short life spans of artisanal fisheries development projects illustrate the problem and the need to revise fisheries development policies and strategies. The problems in each of the projects were varied but related to the pursuit of the government's rural development objectives, poor planning, inaccessible markets, lack of attention to negative environmental changes, lack of understanding of the complex sociocultural conditions, inappropriate human resource development, and lack of evaluation. 


\section{Rural development}

Inshore fisheries development projects constitute an important rural development activity. Unfortunately, they often do not perform well and are mostly short-lived. The problem lies with the somewhat contradictory nature of rural development and fisheries development projects. While rural development projects promote the involvement and participation of rural communities in commercial activities such as artisanal fishing, fisheries development projects demand more cautious planning and implementation that take into account the nature of the resource and the related activities crucial to the operation of the fishing project. Thus, it is important to consider the size of the resource and post-harvest handling and marketing arrangements as part of the fisheries development initiative. Often, inshore fisheries development projects are set up under rural development initiatives. These projects do not last because the resources are quickly exploited to the point of extinction or, alternatively, the people involved disagree because they do not know how to effectively run their operation or differ on the project's management.

The combining of fisheries development projects with rural development initiatives means that the cautious approach needed for better-planned fisheries development is more difficult. Rural development initiatives are quickly adopted by people, making it hard to control the growth of development projects. Such high enthusiasm resulted in the overexploitation of the inshore fisheries and subsequently the failure of projects. This was evident in the majority of the Rural Fisheries Development Program and the Commercial Artisanal Fisheries Development Program projects. The RFTP was attended by people who wanted to have the fishing boats offered to all the trainees. Many of these trainees later lost their boats because they were ill-prepared to operate such ventures. In the end the fisheries resources were depleted and the boat repayments were not met because of insufficient income.

The seaweed-farming project introduced in Fiji in the late 1980s is another failed initiative, although the project was initially well received by the rural communities because of its flexible nature and low skills requirement. The low production by the Fijian farmers and their periodic withdrawal from the project resulted in constant low production and poor quality products, which in the end led to the failure of the project. So, following the initial boom, production stabilised at a low level. The recently introduced seaweed-farming scheme under the CDF is facing a similar fate although it has been claimed as a possible replacement for sugar cane farming. In this case however, the villagers are the mainstays of the industry after having taken up the activity as part of the rural development initiative. 
Operation Veivueti, a collection scheme, was another rural development initiative. The people in rural areas were at first enthusiastic about fishing and selling their catch to the Fiji Army's Auxiliary Unit. However, the initial enthusiasm waned, the people returned to their subsistence schedules and there was little preparation for the return of the collection vessels. Productivity consequently decreased until it was not economical to operate the scheme. By this time, the operation had run into serious financial difficulties that led to accusations of mismanagement and abuse of government resources. In spite of all these failures, Government even as late as 1992 was still trying to organise a collection scheme, this time through the National Trading Corporation (NATCO), the corporate company that replaced the NMA.

\section{Poor project planning}

Although most of the projects were directly related to government development policies, the planning was often poor, hampering successful project implementation. The prawn culture project in Raviravi was a case in point. Despite substantial financial and technical input, production was continually low due to problems that were not foreseen during the planning stages.

The collection schemes were based on the laudable desire to bring the markets closer to people in rural areas, but it was a nightmare to work out an economically viable venture given the nature of transport links and people's complicated dispositions. Further, more recent attempts have been organised despite advice against the viability of such schemes. After conducting studies throughout the Pacific, Carleton (1983), observed that the basic structure of the subsistence sector was not conducive to the regular supply of fish to the urban markets. He then recommended that such schemes be offered only as a social service and only if there is proper planning on how the schemes should operate. In addition, Carleton observed that government officials were ill-equipped to conduct the operations and therefore should not run them. Furthermore, it was important to remember that both the people and the resources were unlikely to support regular intensive collection, and the accumulation of catch over a period of time impossible without proper storage facilities (Evening 1983).

Seaweed farming in Fiji is technically feasible but its cultivation on a commercial basis has not been recommended (McHugh and Philipson 1988). Despite warnings, commercial seaweed farming was undertaken. The project was earmarked for Fijian villagers whose lifestyle was not suited to the requirements of a highly competitive and unstable export-oriented industry. The laid-back attitude and approach of the farmers led to the failure of the industry. 


\section{Inaccessible markets}

Nichols and Moore (1985) argue that the overriding constraint hindering the development of commercial fisheries is the problem of inaccessible markets. Markets are important and are not easily accessible to the people who live in areas far away from the main centres. Markets in rural areas are poor because people have no regular income and live subsistence lifestyles.

There is a need to improve the basic marketing infrastructure. In their report published in 1984, Szabo and Herman described fish handling facilities as running from moderate to poor. Nichols and Moore (1985), in another report a year later, described how developments instituted by the Fisheries Division with the support of Japanese aid were made with the appreciation of the need to get ice supplied to the commercial fisheries in order for it to realise its full potential. Training is needed on post-harvest treatment of the catch and the processing for the production of value-added commodities.

In all the attempts to bring the markets closer to the people, the results have been disappointing because either the resources are over-exploited very quickly or these people just lose interest after a while. All the fish collection schemes to address these problems have not worked well (Adams 1989). The advent of the 'roll-on-roll-off' inter-island ferries has improved the situation for the islands with this service and those close to them. The islands not served by the ferries are still facing the same marketing difficulties as before.

The relative isolation of the export markets from the fishers in rural areas is also a problem. Isolation from markets, the high cost of transportation and the uncertainty of selling products harvested by artisanal fishers makes the likelihood of operating such a market highly unlikely. Furthermore, a great deal of work is needed to improve the quality of locally produced fish if it is to meet the rigorous quality standards that are required in the export markets.

\section{Lack of attention to negative environmental changes}

Prior to the end of the DP9 years (1986-90), the emphasis was on increasing productivity through the use of better fishing techniques, better facilities and better support services. There was no mention of the need for resource management or the sustainable development of the fisheries resource (Fairbairn 1990:259-66).

The main incidences of collapsed fisheries however, brought to the fore the need to ensure that fisheries development was in line with the capacity of the stock to support it. Numerous fisheries reports have alluded to the deteriorating state of the inshore fisheries (Joint Fisheries Strategies Mission 1988; Kailola 1995; Pita 1996; and Preston 1997), but because of poor data, it has not been possible to realistically address the problem. 
It is important, however, that measures are taken to ensure that the ecological carrying capacities of the fisheries resources are used as the basis for development. For instance, now that the customary fishing rights areas have been surveyed and registered, it is time to work out guidelines for their sustainable use. Each of the customary fishing ground-owning units should have some idea of the maximum number of licenses that they can offer. This determination should be based on scientific and economic research and data.

More concerted efforts should be made to promote offshore fisheries. The placement of FADs and the offer of better fishing equipment including boats would be necessary. In addition, more attractive incentives such as better prices and subsidised fuel would enhance the movement offshore. At the moment, the result of the effort to promote offshore fishing has not been satisfactory, resulting in the increased use of inshore resources. The end result has been the depletion of these resources and the subsequent collapse of the fisheries operation.

\section{Complex sociocultural conditions}

The experience with many development projects has illustrated the complex sociocultural predicament of indigenous Fijians. These conditions need to be understood if development projects earmarked for them are to be more successful. The questions of motivation, consistency and the relationship between entrepreneurial skill and Fijian tradition are still to be well understood. With most of the communal fishing boat ventures, the fishing eases off after the boat loan has been repaid. Thus, the outright profits that are to be realised once the boat loan has been cleared are not attained.

Similarly, with seaweed farming, the people rarely maximised production, because the majority of the farmers were content with whatever income they received. The farming was not consistent as some of the farmers left their seaweed farms unattended until harvesting time or only returned to seaweed farming when they needed money.

The same problems were noticeable in the rural fisheries schemes and the fisheries cooperatives. Fishing often eases off after about a year and it becomes unstructured and sporadic. It was normal to find a few active members and a lot of inactive ones. In such schemes only the active members fish regularly and do all the work for the group (Veitayaki et al. 1996). The others are involved only occasionally as they consider themselves part-time fishers.

\section{Inappropriate human resource development}

Human resources development is an important component of fisheries development. For instance, the RFTP has been an essential part of both the Rural Fisheries Development Program and the Commercial Artisanal 
Fisheries Development Program. However, in order for training to be effective it must be appropriate to what the trainees will need to undertake after the courses. First, selection of trainees should be based on some objective criteria. In the past the selection was based solely on proposals from the local communities that were to do the fishing and the endorsement of the tikina (a traditional district) and/or provincial council. In some cases, people ingratiated themselves with their friends and relatives in positions of authority to get them included in the RFTP. Second, during the project, there has been no consideration of the suitability of each candidate to successfully complete the course or carry out their trainee duties. Third, the training must inspire the trainees, since they are expected to lead the fishing operation, train others, and assist in managing the project upon returning to their villages.

The poor selection of trainees in most cases made the trainers' work more complicated given the many skills that have to be transferred. With the limited training period, the trainees were to help build their boat and learn the finer skills of being a fisher, a boat operator and captain, a businessman and a leader. Many of the trainees, for obvious reasons, failed as a result. It is also difficult to imagine how a young trainee, selected to attend the course because of academic skill, could train village members who were older and more experienced fishers. The problem was worse in the villages because the fishers knew each other's competencies and shortcomings.

With seaweed farming, training was not made available to everybody. Although a number of the farmers who did not receive training were fairly successful, the majority had to rely on information from their colleagues and, as such, were only marginally successful, if at all. This was a problem because some of the farmers did not appreciate the care that the seaweed requires and the conditions that would allow for the production of highquality seaweed. As a result there was low productivity of low-grade seaweed resulting in low incomes.

\section{Lack of evaluation}

Evaluation is an important part of a project because it is the stage where the benefits and costs of the project are discussed. Evaluation is also important because it allows the people involved the chance to measure and then improve their performances. Unfortunately, this procedure is often not taken seriously. The result is that problems that affected the performance of the earlier projects are not analysed and therefore people do not learn from their experiences-a precondition for repeating mistakes.

The fisheries collection schemes have been tried on many occasions in Fiji and yet the results have been disappointing. The cultivation of seaweed has again been promoted but already there are signs that the same problems 
of low and inconsistent production and the withdrawal of farmers are still prevalent. Thus the continued use of Fijian farmers despite their poor reputation is a cause for concern.

\section{Proposed policy changes}

Based on my past experiences with specific, failed projects and my understanding of commonly mentioned problems affecting fisheries development projects in Fiji, the following policy changes are recommended.

There is a need for a carefully coordinated and integrated plan and program for the development of inshore resources. The Fisheries Division should be responsible for all fisheries development initiatives, keeping in mind the importance of exerting effective control for the purpose of preventing resource depletion. However, the Fisheries Division should work closely with other government ministries, non government organisations and international development agencies.

The combining of fisheries development with rural development should be carefully planned and monitored. Rural development should concentrate on providing necessary infrastructure and support system, while fisheries development must be cautiously introduced after careful planning and trials that take into consideration the need to keep fisheries development within the carrying capacity of the fisheries resources.

The people selected to be involved in fisheries development projects should be provided with thorough training and should be offered followup courses. The participants at these training sessions should be selected properly using objective selection criteria. There should be understanding of what the project entails and how that relates to the need to manage the fisheries resources. Funding assistance must be offered only to those people who have been adequately trained or have had experience in the fisheries development activity they want to be involved in.

Government should establish reliable and up-to-date databases and information systems to assist in the making of decisions. Therefore, the number of fisheries development permits granted by the owners of customary fishing areas should be based on scientific and economic research and data.

Research should constitute an important area of work for the Fisheries Division. The reliance on estimation based on surveys conducted in the 1970 s is no longer acceptable. The current rate of use and the need for effective management require that future decision making be based on the best available information.

The procedure for granting of permits by the owners of customary fishing areas should be formalised and made more transparent. Fees should be paid to the owners of the customary fishing areas as well as to the 
government. These fees which should be standardised, to ensure the proper management of fisheries resources within the fishing areas.

Government intervention should be selective and must recognise as its ultimate objective the handing over of all commercial functions to the private sector. The private sector must be encouraged to be involved in the development of the fisheries and the marketing of fish and fish products.

A new system of development funding must be formulated to avoid the introduction of unilateral projects and the emphasis on funding periods. The new system must also reduce the number of defaulters and the amount of unpaid debt. In addition, the funding agencies must have the capacity to conduct technical, managerial and financial evaluation of commercial fishing ventures. The project funding period should be abolished and funding agencies should be allowed more flexibility to decide on the use of their funds. Thus, instead of making project funds available for only a defined period of time, the funding agencies could provide the funds whenever appropriate people who are prepared to be involved in a project seek them out.

The earmarking of particular fisheries development projects for special groups, such as indigenous Fijians, should no longer be entertained because most of the people in the villages are not ready to be involved in fisheries development. Instead, only the people that prove they can help themselves should be given the assistance they require.

\section{Conclusion}

Inshore fisheries constitutes an important component of the development sector in Fiji. The government has devised policies and strategies for the development of inshore fisheries resources. Yet, inshore fisheries development up to now has been problematic and expensive. The achievement of the aims and objectives of fisheries development has not been satisfactory. The number of initiatives that have failed are a testimony to the need to adopt a new approach-one that is more appropriate to the socioeconomic conditions in the country and is conducive to the requirements for more successful development. The main issues for inshore fisheries development issues are related to being linked with the pursuit of rural development objectives, poor project planning, lack of attention to negative environmental changes, complex sociocultural conditions, inappropriate human resource development, and lack of proper evaluation procedures.

The proposed policy changes should better address the need to have fisheries development projects that are successful in terms of the benefits to the people involved and the fisheries resources that support the development projects. 